\title{
Some Features of the Syntax of Proverbs in Cameroon Pidgin English
}

\author{
Jean-Paul Kouega \\ University of Yaounde, Yaounde, Cameroon \\ Email:jkouega@yahoo.co.uk
}

How to cite this paper: Kouega, J.-P. (2017) Some Features of the Syntax of Proverbs in Cameroon Pidgin English. Open Access Library Journal, 4: e4139. https://doi.org/10.4236/oalib.1104139

Received: November 10, 2017

Accepted: December 16, 2017

Published: December 19, 2017

Copyright ( 2017 by author and Open Access Library Inc.

This work is licensed under the Creative Commons Attribution International License (CC BY 4.0).

http://creativecommons.org/licenses/by/4.0/

(c) (i) Open Access

\begin{abstract}
This paper examines the structure of Cameroon Pidgin English proverbs. The data are drawn from a sample of proverbs which seem to have originated from the context of use of the language itself and are therefore not translations from foreign languages and cultures. The analysis, which is done following Quirk et al.'s model of syntactic study [1] [2], reveals that simple sentences occur more frequently than compound and complex sentences, with compound sentences being very limited in number. The SVO and SVC clause patterns are dominant in simple sentences and so are positive structures as opposed to negative ones in the whole corpus. Complex sentence proverbs usually contain adverbial and relative clauses. While the position of relative clauses is fixed, that of adverbial clauses is mobile and as a result, cases of fronting are common. Another thematisation technique is clefting, where the element "na" (it is... that) reproduces an earlier sentence constituent and introduces a relative clause in an otherwise simple sentence. This is one of the structural features of Cameroon Pidgin that obviously does not come from the superstrate English; seemingly, it does not come from the substrate Cameroon indigenous languages either.
\end{abstract}

\section{Subject Areas \\ Linguistics, Literature}

\section{Keywords}

Cameroon Pidgin English, Syntax, Proverb, Thematic Fronting, Clefting

\section{Introduction}

This paper is a linguistic analysis of proverbs in Cameroon Pidgin English (CPE), a variant of West African Pidgins spoken along the West Coast of Africa 
from Ghana down to Cameroon. It is a language that came into being in Cameroon during the Slave Trade years (1400-1800), and it was the only language in which Slave traders and the indigenes communicated. When trade shifted from slaves to manufactured goods, this same language continued to be used and this went on from 1800 to 1884 . When the Germans arrived in 1884, Pidgin was a fully developed language and, to check its spread, they put a ban on its use. Later on, they found it difficult-practically impossible-to communicate with the indigenes and so, they had no choice but to lift this ban and use Pidgin for their colonisation programme. Since then, the language has been evolving and today it is attested in various other domains besides trade. This work is divided into four sections entitled background to the study, review of past works on proverbs, methodology adopted for the work, and analysis of the data collected. These are considered in turn.

\section{Background to the Study}

As early as 1960, Cameroon Pidgin English became the object of a number of scientific investigations. Schneider [3]-[8], Todd [9] [10], Menang [11] [12], Mbangwana [13] [14], Todd \& Jumban [15], Ayafor [16] and Ngefac and Sala [17], and Sala and Ngefac [18] examined various aspects of its linguistic structure. Todd [19] devoted a book chapter to the description of aspects of its phonology, lexis and syntax. Recent works are scarce: Mbakong Tsende [20] discussed some aspects of Pidgin verb phrase constituents, Leoue [21] took up the nominal group, Anchimbe [22] looked into one specific type of verb inflection, Ayafor [23] considered aspects of the morphology and syntax of the language. Lastly, Kouega [24] compiled a 3000 word dictionary which gives a preliminary account of the size and nature of CPE's lexical inventory based on one type of data, the spoken media; seven years later, words from other sources like the market place, politics, trades etc were added to it, which yielded a 300-page dictionary (Kouega [25]). Latest works of a certain size include Ngefac [26] and Nkemngong Nkengasong [27].

The bulk of research on CPE is sociolinguistic in nature (Mbassi-Manga [28]; Féral [29] [30] [31]; Mbangwana [32]; Alobwede [33]; Kouega [34]; Mbufong [35], Schröder [36], Simo Bobda and Wolf [37], Ayafor [38], Echu [39]). These works all show that CPE is a major lingua franca in Cameroon and, above all, it is used even in the localities where other major and minor lingua francas like Ewondo Populaire, Fulfulde, Arab Choa (Kouega [40]) are dominant. In Anglophone Cameroon, in particular, Pidgin English is the most frequently used language in the home, the neighbourhood and the schoolyard. It is common in religion (Mbangwana [32]; actually, the Catholic Church has adopted it as the language of preaching in rural areas (Kouega and Emaleu [41]), and it has been publishing prayer books and extracts of the Gospel in it (Catholic Mission [42] [43]). Recently, the proportion of its use in the spoken media became significant, as all new private radio stations have programmes in it (see list in Kouega [40]. 
Despite its widespread use, both educated and non-educated Anglophone Cameroonians have a negative attitude to it (Kouega [34], Echu [39]). Secondary school regulations punish pupils who use it in school premises. On the campus of the University of Buea in the Southwest region, there are postings mandating students to keep Pidgin English out of the gate. Worse, parents put forward the claim that they would unanimously vote against its introduction in the school system as the medium of instruction in the early years of primary education (Kouega [24]), as they strongly believe it would interfere with their children's acquisition of English (Beteck [44], Munang [45]), a belief which Ayafor [46], Fontem [47], Fontem and Oyetade [48] and Neba, Chibaka and Atindogbe [49] do not share. In Cameroon today, CPE and Standard English form a continuum (Kouega [50]), with illiterates having only CPE, the basilectal variety, as their out-group language and educated people being capable of using English as well. In-between these two extremes are semi-education people, who can hardly keep the two varieties apart.

While the linguistic works cited so far focused on language in its social context and on lower level linguistic elements, one study (Kouega [51]) tackled a higher level of language patterning i.e. discourse; it considered market transactions in CPE, using the model of discourse analysis initiated by Sinclair and Coulthard [52]. The study revealed that bargaining, which is realised with both linguistic and non-verbal cues involving swearing, begging, insisting, persuading and other persuasive tones of voice and postures, was the central element of market transactions [53]. Another study (Kouega [54]) took up telephone conversations, focusing on their beginnings and endings and using the model of discourse analysis developed by Schegloff and Sacks [55] and Coronel-Molina [56]. The study outlined the various linguistic features that users exploit to perform such communicative functions as checking the channel, greeting, checking callers' identity or terminating an interaction. It also identified a number of cultural features that surface in telephone conversations, like the habit of using a series of prayers to God to signal pre-closing sequences. These linguistic and cultural practices are widespread and some of them have even permeated into L2 English in Cameroon (Kouega [40]).

\section{Review of Literature}

This section considers works on proverbs in general and Cameroon Pidgin English proverbs in particular.

\subsection{Works on Proverbs}

These works usually consider the origin of proverbs, their syntactic structures, their sound patterns and occasionally their thematic categories. Mieder [57], a leading figure in paremiology, identified four sources for the distribution of European proverbs. A first source is Greek and Roman antiquity: proverbs from this source are found in the works of scholars like Plato, Sophocles and Homer, 
to name only these few. These proverbs were translated into various European languages and, as a result, they do have word-for-word equivalents in nearly all European languages. Here are a few illustrations in English:

Barking dogs do not bite.

Love is blind.

One hand washes the other.

One swallow does not make summer.

Still waters run deep.

Walls have ears.

Where there is smoke there is fire.

A second source of proverbs for the entire European continent and beyond is the Bible, whose proverbs date back to classical antiquity. Here are a few illustrations:

A prophet is without honour save in his own country.

An eye for an eye, a tooth for a tooth.

As you sow so you reap.

Do as you would be done by.

He that will not work, shall not eat.

He who digs a pit for others, falls in himself.

There is nothing new under the sun.

The third source for common European proverbs is Medieval Latin. Actually in the Middle Ages, Latin had attained the status of a lingua franca:

All roads lead to Rome.

All that glitters is not gold.

At night, all the cats are grey.

Clothes do not make the man.

Crows will not pick out crows' eyes.

New brooms sweep clean.

No rose without horns.

Strike when the iron is hot.

The fourth source for common European proverbs is the mass media, which reverses the historical move of proverbs from Europe to the United States:

A picture is worth a thousand words.

It takes two to tango.

Garbage in, garbage out.

Phonic proverbial studies identify such patterns as assonance, alliteration, consonance and rhyming (Lindstromberg [58]). Thematically, proverbs are said to fall into various categories; in a description of the Dongolawi Nubian language proverbs, Taha [59] revealed that they cover general themes like cooperation, collaboration, marriage and family issues, advice and guidance, warning and greed. Owomoyela [60] discussed the aesthetic and poetic values of Yoruba proverbs, like sarcasm, humour, irony and the like on the one hand and their utilitarian or didactic function on the other. The linguistic features of proverbs 
have interested a few researchers. Bamgbose [61] looked into the form of Yoruba proverbs, identifying what features "make them so striking as a literary form in Yoruba". He found that they are made up of simple, complex, sequential and parallel sentences on the one hand, and that they are characterised at the lexical level by features of repetition, contrast and word play on the other. Examining syntactic proverbial markers in the Irish language, MacCoinnigh [62] found that the simple sentence is dominant (57\% of 1000 tokens), far above complex sentences $(27 \%)$ and compound ones (8\%), the remainder being phrasal proverbs.

\subsection{Works on Cameroon Pidgin Proverbs}

The first sample of Cameroon Pidgin proverbs was collected by Schneider [6] but Todd [63] is the only other researcher who has devoted a full article to this domain. Her data were picked out from her conversations with Bamenda Grasslanders in the course of a few hours of contact with them. From her broad corpus she removed the proverbs that were already recorded by Schneider [6] and was left with a total of 82 tokens. The analysis of these 82 tokens revealed that four proverbs i.e. 5\%, were drawn directly from Standard English (as the examples 1 - 2 below show), 16\% had parallels in at least one of the Cameroon vernaculars (e.g. 3 - 4 below), 14\% almost certainly arose in Cameroon (e.g. 5 - 6 below), 40\% had analogues in Krio (e.g. 7 - 8 below) and 29\% were of unknown sources (e.g. 9 - 10 below). These ten illustrative proverbs, which are converted into the writing convention outlined in Kouega [24] p. 31, are reproduced below, together with the explanations provided by Todd.

1) Eni man fo yi sef Got fo wi ol.

(Any man for he self God for we all. $\approx$ Every man looks after his own interests, God looks after us all.)

2) Got no di slip.

(God not sleep. $\approx$ God is aware of everything.)

3) Eni alata na kin fo yi hol.

(Any rat is king in his hole. $\approx$ Everyone has a sphere of influence in which he is most important./ The beetle in its hole is a sultan.)

4) Tifman yi fam na soso medesin.

(Thief his farm is so so medicine. $\approx \mathrm{A}$ thief knows how to secure his property against theft.)

5) Di tin we yi bin du kaka di sem tu go du kofi.

(The thing which did cocoa the same too will do coffee. $\approx$ That which brought about disaster to the cocoa industry will also ruin coffee (i.e. we rarely learn from past misfortunes.)

6) Mimbo kech alata plenti sef yi no di silip fo pusi yi bet.

(Wine catch rat plenty even he no sleep for pussy he bed. ₹No matter how drunk a rat is he does not go to sleep in a cat's bed./Rats never sleep on the mat of the cat.)

7) Bat bush no de fo trowe bat pikin. 
(Bad bush not be for throw-away bad child. ₹No matter how bad a child is his parents will not want to get rid of him.)

8) Jam pas dai monki chop pepe.

(Poverty surpass die monkey eat pepper. $\approx$ When pressed by necessity one will make do with very little.)

9) Ai no di shut bif.

(Eye no shoot beef. $\approx$ It cannot do any harm to look.)

10) Man pas yu, hol yi bat.

(Man pass you hold his bad. $\approx$ If someone is better than you, you can always find consolation by concentrating on his weaknesses).

\section{Methodology}

Informants were fluent speakers of Pidgin English, especially uneducated or low education people (market women, labourers, truck drivers...) in the Southwest and Northwest regions of Cameroon. They interacted with the researcher and his assistants either individually or in groups. The most rewarding settings were pubs where a few bottles of drinks were offered to the informants, bus stations while passengers were waiting for their buses to take off and market places during shopping. Given the nature of the settings of the study (pubs, market places, coach stations...) and the fact that the respondents sometimes answered in chorus, it is difficult to tell how many people took part in the exercise and to provide detailed demographic information on each of them. Impressionistically their ages ranged from 25 to 75 years. The materials presented to them were proverb-like utterances extracted from a collection of Cameroon Pidgin English texts, the tagging of which will start immediately funding from any source is secured. From Mieder's observation [64] (p. 119) that "proverbs are short, generally known sentences of the folk...", a sentence completion test was designed and conducted orally. The initial fragment of each of these proverb-like utterances was read out to these informants for them to invoke the entire proverbs. When a fragment of an utterance was quoted and the informants spontaneously completed it, that utterance was marked as a potential proverb. When, on the contrary, the expected element was not supplied instantly, that utterance was rejected. Below are two illustrations numbered (11) and (12), where A stands for the research team and $\mathrm{B}$ for the informants:

(11)
A. Akwara no get...
B. (in chorus)... chois!
(hence: Akwara no get chois, literally "A prostitute does not have choice" $\approx$ Beggars can't be choosers.)
A. If yu mek yasef raip ba...
B. (in chorus)... nana, monki go chop yu.
(hence: If yu mek yasef raip banana, monki will chop yu, literally "If you make 
yourself ripe banana, monkey will eat you" $\approx$ Stand up and fight for your rights.)

As (12) above shows, popular proverbs are known by every one; this explains why the informants uttered the last two syllables of the word "banana" immediately the first syllable "ba-" was pronounced.

This oral sentence completion test technique was conducted in the Southwest region of Cameroon first, as this region is where Pidgin started up in the country and later spread into the hinterland. Here, a handful of proverb-like utterances identified in the Pidgin text collection including some proverbs drawn from Todd's sample [65] were rejected. The proverbs which passed this test in the Southwest region were then taken to the Northwest region, where the same exercise was carried out in similar settings. What came out constituted the broad corpus for this study. The next step consisted in working out a narrow corpus i.e. a set of proverbs that developed in the Cameroon culture and did not therefore originate from European languages. The researcher and his team members went over the list and identified the proverbs numbered 13 to 24 below as European-based and removed them. The remaining 82 proverbs in the list (6 running pages) were further subjected via e-mail to the appreciation of a handful of literature teachers whose addresses were got from the web sites of universities. Five teachers responded: one each from American, British and Zambian universities, and two from Cameroonian universities. They were asked to indicate which of these 82 proverbs they had ever come across in the course of their reading. Cameroonian teachers reported that they had overheard some of them in political rallies or in church while foreign teachers were rather amused by the inventiveness of Cameroon Pidgin speakers. From these respondents' comments, one can claim that these 82 proverbs, which constitute the narrow corpus for this study, are actually home-grown.

(13) Bit dai hos.

(Beat dead horse. $\approx$ Don't beat a dead horse. (English)

(14) De no di gi fawo chop fo maket de. (French)

(They not give fowl food on market day. ₹lit. We do not feed fowls on the market day.)

(15) Emti pot di mek tu moch nois. (English)

(Empty pot make too much noise. $\approx$ Empty vessels make much noise.)

(16) Fo kontri fo blain pipul wan ai-man na kin. (French)

(In country of blind people one eye-man is kin. $\approx$ In a country of blind people, a one-eyed man is a king.)

(17) From frapan tu faja. (English)

(From frying pan to fire. $\approx$ From the frying pan into the fire.)

(18) Got di chop fo ples we de tai yi. (French)

(Goat eat at place where they tie it. $\approx$ A goat feeds where it is tied.)

(19) If yu fain-am yu go si-am (French)

(If you search it, you will see it. $\approx$ If you look for trouble, you will have it.)

(20) Kot ya kot akodin to ya sais. (English) 
(Cut your coat according to your size.)

(21) Laik mami laik yi pikin. (French)

(Like mother like her child. $\approx$ Like father, like son.)

(22) Wan man yi mit na som ara man yi poisin. (English)

(One man his meat is some other man his poison. $\approx$ One man's music is another man's noise.)

(23) Wen pusi no de arata di dans. (French)

(When cat not there, rat dance. $\approx$ When the cat is not there, rats dance.)

(24) Wol get ie. (English)

(Wall get ear. $\approx$ Walls have ears.)

\section{Analysis}

The most salient structural patterns identified in the narrow corpus are outlined here, under the following three headings: sentence types, sentence classes and sentence length, and negation and thematic fronting. These are considered in turn.

\subsection{Sentence Types}

Structurally, Quirk et al. [1] [2] group sentences into three broad types labelled simple, compound and complex; any structure that does not fit squarely into these types is referred to as a minor sentence. Simple sentences contain just one clause while compound and complex sentences contain at least two clauses. The clauses of compound sentences are usually linked by a coordinator like "and" while those of complex sentences are usually linked by a subordinator like "before". As for minor sentences, they may be formulae, greetings and interjections. Here is an example of each type:

I quickly shut the door. (simple sentence)

He heard an explosion and he phoned the police. (compound sentence)

I quickly shut the door before the animal could escape. (complex sentence)

You and your statistics! (minor sentence)

An attempt to group Pidgin proverbs into these four sentence types gives the results in Table 1.

As Table 1 shows, most Pidgin proverbs are simple sentences $(42.68 \%$ of 82 tokens); this result replicates MacCoinnigh's finding [62] (2013) i.e. the simple sentence was the dominant structure in a collection of Irish proverbs $(57 \%$ of 1000 tokens). In the corpus, simple and complex sentence proverbs together form close to $80 \%$ of the tokens. Each of these four sentence type proverbs is

Table 1. Proverb sentence types.

\begin{tabular}{cccccc}
\hline Proverbs & $\begin{array}{c}\text { Simple } \\
\text { sentences }\end{array}$ & $\begin{array}{c}\text { Compound } \\
\text { sentences }\end{array}$ & $\begin{array}{c}\text { Complex } \\
\text { sentences }\end{array}$ & $\begin{array}{c}\text { Minor } \\
\text { sentences }\end{array}$ & Total \\
\hline $\begin{array}{c}\text { Number } \\
(\text { Percentage })\end{array}$ & 35 & 12 & 30 & 5 & 82 \\
$(42.68 \%)$ & $(14.63 \%)$ & $(36.59 \%)$ & $(6.1 \%)$ & $(100 \%)$ \\
\hline
\end{tabular}


considered next, beginning with the simple sentence type.

\subsubsection{Simple Sentence Type Proverbs}

These are proverbs which contain only one clause. Examining English clauses in their simple declarative form, Quirk et al. [1] [2] observed that they contained the following obligatory sentence elements: Subject (S), Verb (V), Complement (C), Adverbial (A), and Object (O). Using these elements as a starting point, they grouped simple sentence clauses into seven types, labelled:

SVC: Mary is kind.

SVA: Mary is here.

SV: The child was laughing.

SVO: Somebody caught the ball.

SVOC: We have proved him wrong.

SVOA: I put the plate on the table.

SVOO: She gives me expensive presents.

A similar grouping can be applied to proverbs, as the following examples (25 30) show:

SVC: Jumba no bi marit. (25)

(Concubinage is not marriage. $\approx$ Concubinage/cohabitation is not marriage.)

SVA: Yu di shit na fo ya rot. (26)

(You are excreting it is on your road. $\approx$ You are excreting on your own road. / You are harming yourself))

SV: Wan bangul no di hala. (27)

(One bangle not ring. One bangle does not ring/make noise. $\approx$ It takes two to tango./ One hand washes the other.)

SVO: Ai no di shut bif. (28)

(Eye not shoot beef/animal. Eye does not shoot animal. $\approx$ Looking at something does not change it.)

SVOA: No put san-san fo man yi gari. (29)

(Not put sand in someone his gari. $\approx$ Do not prevent someone from getting an advantage.)

A count of these patterns gives the following result presented in Table 2.

As Table 2 shows, the SVO and SVC clause types are dominant as, together, they make up close to $60 \%$ of 35 cases.

\subsubsection{Compound Sentence Type Proverbs}

Compound sentences are said to include at least two clauses linked by a coordinator as the example above illustrates. Such compounds which actually contain an explicit coordinator are non-existent in the proverb corpus. Common

Table 2. Simple sentence proverb clause types.

\begin{tabular}{ccccccccc}
\hline Proverbs & SVC & SVA & SV & SVO & SVOC & SVOA & SVOO & Total \\
\hline & 10 & 6 & 2 & 11 & 6 & & \\
& $(28.57 \%)$ & $(17.14 \%)$ & $(5.71 \%)$ & $(31.43)$ & & $(17.14 \%)$ & & 35 \\
\hline
\end{tabular}


structures are compounds with an implicit coordinator, like 30 - 33 below:

30) Chop foget tomoro.

(Eat forget tomorrow. $\approx$ Someone who eats today and forget the following day. $\approx$ Do not squander all your resources today; save some for the future.)

31) Ova sabi kari basket.

(Over know, carry basket. $\approx$ He who pretends to know everything is easily duped.)

32) Win don blo wi don si faul yi shit hol.

(Wind has blow we have see fowl its shit hole./The wind has blown and we have seen the fowl's anus. $\approx$ Thanks to a mistake, we now have some compelling evidence./He has let the cat out of the bag.)

33) Yu don pik ston, dok si-am.

(You have pick stone dog see it./ You have picked a stone to hit a dog and the dog has seen it. $\approx$ We have discovered your plans and you can no longer cheat us.)

Occasionally, some compounds include conjoins having approximately the same number of syllables separated by a pause occurring at the point where a coordinator could have been inserted, a process known as asyndetic coordination. This can be illustrated by examples 34 - 38 below:

34) Giv ashia, kari kenja.

(Give sympathy, carry basket. $\approx$ You have come only to help him but now you are doing the whole job. )

35) Man pas yu, kari yi bak.

(Man surpass you, carry his back. ₹If you can't beat someone, join him.)

36) Monki wok, babun chop.

(Monkey work, baboon eat. $\approx$ Poor people work, rich ones reap the fruit.)

37) Na ya mbanga, na ya oya.

(It's your palm nut, it's your palm oil. $\approx$ Mind your business.)

38) Tiko drin, Kumba dron.

(Tiko drink Kumba drunk./Tiko drinks and Kumba gets drunk. $\approx$ The cow is giving birth but the bull's tail hurts.)

Some compound sentences can easily be converted into complex sentences. Take for example 39a) and 39b) below:

39a. Du mi, A du yu, Got no go veks (original form)

(Do me, I do you, God not will angry./Hit me and I hit you back and God will not be angry $\approx$ An eye for an eye.)

39b. If yu du mi an A du yu, Got no go veks. (conjunctions inserted)

If you hit me and I hit you, God will not be angry.

\subsubsection{Complex Sentence Type Proverbs}

They are usually introduced by various indicators including the following: presence of more than one verb, of subordinators like "if" (if), "se" (that), "we" (where), "ontil" (until), "wen" (when) and of the item "na" (it is ...that) etc. Depending on the subordinators, the embedded clause may be relative, nominal, 
adverbial or comparative, as the following examples show:

The book which is on the table is Mary's. (relative)

I told him that he was wrong: (nominal)

Buy your tickets as soon as you reach the station. (adverbial)

Mary is less old than Jane is. (comparative)

Similar structures are found in proverbs, as these examples (40 - 43) show:

40) Han ya bak fo ples we yu fit muv-am. (relative)

(Hang your bag at place where you can remove it. $\approx$ Do not chew more than you can swallow.)

41) Bobolo di laf koki se dem don tai yi nek. (nominal)

(Cassava paste is laughing beans paste that they have tied its neck. $\approx$ Monkeys laugh at the buttocks of other monkeys.)

42) If fawo no hie "shhh", yi go hie "bang". (adverbial)

(If fawo not hear "shhh", it will hear "bang". ₹If someone does take any advice, he will soon run into problems.)

43) Blot tik pas wata. (comparative)

(Blood thick more than water. $\approx$ Family bonds are tight.)

The count of these complex structures is presented in Table 3 below.

Table 3 shows that adverbial clauses (36.67\% of 30 cases), which are introduced by conjunctions like "if" (if), "ontil" (until) and "wen" (when), are the most frequently found pattern. Relative clauses (26.67\%) are introduced by the conjunction "we" (which, that) while comparative clauses (6.67\%) are indicated by the marker "pas" (more than). Nominal clauses (3.33\%) are rare: the lone case identified is introduced by the conjunction "se" (that); it follows the verb "laf" (laugh), which is transitive in this language. The last category labelled "others", which includes clauses introduced by the word "na" (it is... that), is considered later.

\subsection{Sentence Classes and Sentence Length}

As Quirk et al. [1] [2] point out, simple sentences are divided into four major syntactic classes labelled statements, questions, commands and exclamations. Statements are sentences in which the subject is always present and generally precedes the verb. Questions are marked by the fronting of an auxiliary, or a wh-word, or by associating the falling tone with a statement. Commands are sentences with no overt grammatical subject, with their verb always in the imperative mood. Exclamations have an initial phrase introduced by "what" or "how". Below are reproduced instances of each type:

John will speak to the boss. (statement)

Table 3. Types of complex sentence proverbs.

\begin{tabular}{ccccccc}
\hline Proverbs & Relative & Nominal & Adverbial & Comparative & Others & Total \\
\hline & 8 & 1 & 11 & 2 & 8 & \multirow{2}{*}{$(26 \%)$} \\
& $(26.67 \%)$ & $(3.33 \%)$ & $(36.67 \%)$ & $(6.67 \%)$ & $(26.67 \%)$ & 30 \\
\hline
\end{tabular}


Will John speak to the boss today? (question)

Speak to the boss! (command)

What a noise they are making! (exclamation)

An attempt at grouping proverbs into these four classes yielded the results outlined in Table 4.

As Table 4 shows, $85 \%$ of 82 proverbs are statements while $15 \%$ are commands. Interestingly, questions and commands are non-existent. This finding corroborates Dundes' observation [65] that proverbs are generally declarative.

An attempt was made to check the word length of each token. The shortest proverbs were found to have three words while the longest had 18 words, as 44 46 show. When the total number of words making up the 82 proverbs was counted, it was found that the mean proverb word length was 6.79 .

44) Jelosi na puo.

(Jealousy, it is poverty./Jealousy comes from poverty.)

45) Kongosa na fie.

(Gossiping, it is fear. Gossiping comes from fear./You gossip because you are afraid of someone.)

46) Tin we ol man di si-am yi di shidon, yon man no fi si we yi tanap.

(Thing which old man is seeing it he is sitting down, young man not can see that he stand up. What an old man can see sitting down, a young man cannot see it standing up.)

Interestingly, no relationship was found to exist between sentence length and sentence complexity or sentence classes.

\subsection{Negation and Thematic Fronting}

Negative sentences contain the negator "not", other negators being "no", "never", "nowhere" etc. Structurally, these negative elements are inserted into various sentence constituents of a positive sentence, as in: "I am coming." and "I am not coming." Proverbs are either positive like (47) or negative like (48):

47) Ol dai na dai. (positive)

All death it is death./ Death is death.)

48) Devul no di flop berigron. (negative)

(Devil not is full cemetery. The devil is not satisfied with the many corpses in cemeteries.)

The proportion of positive and negative proverbs in the corpus is outlined in Table 5.

As Table 5 reveals, positive proverbs (60.98\%) are more frequent in the corpus than negative ones and there seems to be no relationship between these structures and sentence classes or sentence types.

Table 4. Proverb sentence classes.

\begin{tabular}{|c|c|c|c|c|c|}
\hline Proverbs & Statements & Questions & Commands & Exclamations & Total \\
\hline & $70(85 \%)$ & & $12(15 \%)$ & & 82 \\
\hline
\end{tabular}


Table 5. Positive and negative proverbs.

\begin{tabular}{cccc}
\hline Proverbs & Positive & Negative & total \\
\hline $50(60.98 \%)$ & $32(39.02 \%)$ & 82 \\
\hline
\end{tabular}

Regarding thematic fronting, it should be noted that some sentence constituents may be manipulated to express prominence. Generally, the natural place of occurrence of a given sentence element is known; for example, the initial element of an SVC sentence is the subject, as the sentence "His name is Joe." shows. Here, "his name" is the subject and it occurs first. However, for stylistic reasons, the C element may be fronted, as in: "Joe his name is." Similarly in a sentence like "John wore his best suit...", any element may be highlighted. Take for example these two cases: "It is John who wore the best suit..." and "It is his best suit that John wore..."; here John is highlighted in the first case and "his best suit" is highlighted in the second case. Such structures are referred to as cleft sentences.

Thematic fronting in proverbs usually involves adverbial clauses, which may begin with the main or the subordinate clause, as shown below:

49) Kao no no yus fo yi tel ontil wen de kot-am. (main clause at initial position)

(Cow not know use of its tail until when they cut it. $\approx$ Someone does not know the importance of something until he is deprived of it.)

50) Wen somtin tu moch yi no di swit. (subordinate clause at initial position)

(When something too much it not is sweet. $\approx$ Too much of a thing is a disease./ All good thing must come to an end.)

The count of proverbs in these two positions gives the result presented in $\mathrm{Ta}$ ble 6:

Table 6 indicates that fronted subordinate clauses represent $62.5 \%$ of the 8 cases. Structurally, these clauses are usually introduced by the conjunctions "if" and "when".

Thematic fronting in proverbs also involves cleft sentences. These are sentences in which a specific element is highlighted by the marker "na" (it is... that). This marker may be the very first sentence element as in 51) or it may be preceded by another sentence element as in 52) below:

51) Na diferen man yi pikin yi shit di smel.

(It is different man his child his faeces are smelling. $\approx$ It is the faeces of someone else's child that smell.)

52) Man yi hat na yi beli sabi-am.

(Man his heart it is his belly that know it./It is the belly of a man that can tell what is in his heart. $\approx$ You can't tell what someone has in mind.)

\section{Conclusion}

This paper has shown that Cameroon Pidgin proverbs have a specific sentence structure containing mainly simple and complex sentences. Embedded clauses 
Table 6. Fronted proverb constituents.

\begin{tabular}{cccc}
\hline Proverbs & Fronted main clause & Fronted subordinate clause & Total \\
\hline 3 & 5 & 8 \\
$37.5 \%$ & $62.5 \%$ & \\
\hline
\end{tabular}

are usually either adverbial or relative, and sentences are generally statements, hardly questions or exclamations. The average length of proverbs is about seven words, with the shortest being barely three words and the longest 18 words. Over two-thirds of proverbs are positive, the remainder being negative. Adverbial clause type proverbs usually occur in thematic position, with the bulk of them introduced by the conjunctions "if" and "when".

The scope of this paper is limited to the syntax of home-grown proverbs. Future research can consider borrowed proverbs, focusing on how they are adapted in Cameroon Pidgin and how these adaptations make the resulting proverbs different from or similar to the home-grown ones described here. When this is done, an interested researcher may investigate whether the proverbs in Cameroon Pidgin constitute a marked domain within the overall syntax of the variety or whether their sentences are just like other sentences in the variety. This can be done effectively only after a comprehensive study of the syntax of this variety has been carried out. Other areas of interest are the lexical and stylistic features of proverbs which, as the review above shows, have not yet been tackled.

\section{References}

[1] Quirk, R., Greembaum, S., Leech, G. and Startvik, J. (1972) A Grammar of Contemporary English. Longman, London.

[2] Quirk, R., Greembaum, S., Leech, G. and Startvik, J. (1985) A Comprehensive Grammar of the English Language. Longman, London.

[3] Schneider, G.D. (1960) Cameroons Creole Dictionary. Unpublished Manuscript, Bamenda.

[4] Schneider, G.D. (1963) First Steps to Wes-kos. Hartford Seminary Foundation, Hartford.

[5] Schneider, G.D. (1965) A Preliminary Glossary English-Pidgin English. Unpublished Manuscript, Bamenda.

[6] Schneider, G.D. (1965) Pidgin English Proverbs. African Monographs No 6, Michigan State University.

[7] Schneider, G.D. (1966) West African Pidgin English: A Descriptive Linguistic Analysis with Texts from the Cameroon Area. Hartford Seminary Foundation, Athens, Ohio.

[8] Schneider, G.D. (1967) West African Pidgin English-An Overview: PhonologyMorphology. Journal of English Linguistics, 1, 47-56. https://doi.org/10.1177/007542426700100106

[9] Todd, L. (1974) Pidgins and Creoles. Routledge and Kegan Paul, London. https://doi.org/10.4324/9780203381199

[10] Todd, L. (1979) Some Day Been Day. Routledge and Kegan Paul, London.

[11] Menang, T. (1979) Trends in Cameroon Pidgin English lexicology. MA Degree 
Thesis, University of Yaounde, Yaounde.

[12] Menang, T. (2004) Cameroon Pidgin English (Kamtok): Phonology. In: Schneider, E.W., Burridge, K., Kortmann, B., Mesthrie, R. and Upton, C., Eds., A Handbook of Varieties of English, Vol. 1: Phonology, Mouton de Gruyter, Berlin, 903-917.

[13] Mbangwana, P.N. (1991) Kamtok Is Achieving Its Letters de Noblesse. Lore and Language, 10, 59-65.

[14] Mbangwana, P.N. (2004) Pidgin English in Cameroon: A Veritable Linguistic Menu. In Echu, G. and Gyassi Obeng, S., Eds., Africa Meets Europe: Language Contact in West Africa, Nova Science Publishers, New York, 22-44.

[15] Todd, L. and Jumban, M. (1992). Kamtok: Anatomy of a Pidgin. English Today, 29, 3-11. https://doi.org/10.1017/S0266078400006052

[16] Ayafor, M. (1996) An Orthography for Kamtok. English Today, 12, 53-57. https://doi.org/10.1017/S0266078400009317

[17] Ngefac, A. and Sala, B.M. (2006) Cameroon Pidgin and Cameroon English at a Confluence: A Real-Time Investigation. English World-Wide, 27, 217-227. https://doi.org/10.1075/eww.27.2.06nge

[18] Sala, B.M. and Ngefac, A. (2006) What's Happening to Cameroon Pidgin? The Depidginisation Process in Cameroon Pidgin English. PhiN 30/2006, 31-43. http://web.fu-berlin.de/phin/phin36/p36t3.htm

[19] Todd, L. (1984) Modern Englishes: Pidgins and Creoles. Blackwell, Oxford.

[20] Mbakong Tsende, A. (1993) Predication et marqueurs aspecto-temporels du Pidgin English camerounais. Journal of West African Languages, 23, 45-58.

[21] Leoue, J.G. (1996) Nominal Determination-Focus on a Few Operations in Cameroon Pidgin English. Master Degree Dissertation, Université de la Sorbonne Nouvelle III. https://vtechworks.lib.vt.edu/bitstream/handle/10919/71564/290_1.pdf?sequence=1

[22] Anchimbe, E.A. (2004) The "V+AM" Objective Pronoun Inflection in Cameroon Pidgin English (CPE).

[23] Ayafor, M. (2004) Cameroon Pidgin English (Kamtok): Morphology and Syntax. In: Kortmann, B., Burridge, K., Mesthrie, R., Schneider, E.W. and Upton, C., Eds., $A$ Handbook of Varieties of English, Vol. 2: Morphology and Syntax, Mouton de Gruyter, Berlin, 909-928.

[24] Kouega, J.P. (2008) A Dictionary of Cameroon Pidgin English Usage: Pronunciation, Grammar and Vocabulary. Lincom Europa, Muenchen.

[25] Kouega, J.P. (2015) A Dictionary of Cameroon Pidgin English Usage: Pronunciation, Grammar and Vocabulary. Lincom Europa, Muenchen.

[26] Ngefac, A. (2016) Sociolinguistic and Structural Aspects of Cameroon Creole English. Cambridge Scholars Publishing, Cambridge.

[27] Nkengasong, N. (2016) A Grammar of Cameroonian Pidgin. Cambridge Scholars Publishing, Cambridge.

[28] Mbassi-Manga, F. (1973) English in Cameroon: A Study of Historical Contacts: Patterns of Usage and Current Trends. PhD Thesis, Leeds University, Leeds.

[29] Féral, C. (1978) Le Pidgin English au Cameroun. Conseil international de la langue française. SELAF, Paris.

[30] Féral, C. (1980) Le Pidgin English camerounais: Essai de définition linguistique et sociolinguistique. Doctorat de 3e Cycle Thesis, Université de Nice.

[31] Feral, C. (1989) Pidgin-English du Cameroun: Description linguistique et 
sociolinguistique. Peeters/SELAF, Paris.

[32] Mbangwana, P.N. (1983) The Scope and Role of Pidgin English in Cameroon. In: Koenig, E.L., Chia, E. and Povey, J., Eds., A Sociolinguistic Profile of Urban Centers in Cameroon, Crossroads Press, Los Angeles, 79-92.

[33] Alobwede, C. (1998) Banning Pidgin English in Cameroon. English Today, 14, 55-60.

[34] Kouega, J.P. (2001) Pidgin Facing Death in Cameroon. Terralingua. http://www.terralingua.org/publications/Langscape/LS21.pdf

[35] Mbufong, P. (2001) Pidgin English in Anglophone Cameroon. English Today, 17, 52-53.

[36] Schröder, A. (2003) Status, Functions and Prospects of Pidgin English. Gunter Narr Verlag, Tübingen.

[37] Simo Bobda, A. and Wolf, H.G. (2003) Pidgin English in Cameroon in the New Millennium. In: Lucko, P., Peter, L. and Wolf, H.G., Eds., Studies in African Varieties of English, Peter Lang, Frankfurt, 101-117.

[38] Ayafor, M. (2006) Kamtok (Pidgin) Is Gaining Ground in Cameroon. In: Chia, E., Ed., African Lingistics and the Development of African Communities, CODESRIA, Senegal.

[39] Echu, G. (2007) The Politics about Cameroon Pidgin English. Annals of the Faculty of Arts, Letters and Social Sciences, 1, 133-150.

[40] Kouega, J.P. (2007) The Language Situation in Cameroon. Current Issues in Language Planning (CILP), 1-94. https://doi.org/10.2167/cilp110.0

[41] Kouega, J.P. and Emaleu, C.S.T. (2013) Language Choice in Multilingual Socio-Religious Settings: The Case of Semi-Urban Localities in the Southwest Region of Cameroon. World Englishes, 32, 403-416.

[42] Catholic Mission (1974) Holy Week Lectionary in Pidgin English. Catholic Printing Press, Buea.

[43] Catholic Mission (1981) Pidgin English Prayer Book. Vatican Polyglot, Vatican.

[44] Beteck, A.B. (1986) The Influence of Kamtok (Cameroon Pidgin English) on the Use of English Language in Cameroon. Unpublished Maîtrise Dissertation, University of Yaounde, Yaounde.

[45] Munang, I.A. (1996) Cameroon Pidgin English (CPE) Interference in Standard English (SE) Lexical Usage: A Case Study of Language Use among Anglophone Cameroonians. Unpublished Maitrise Dissertation, University of Yaounde I, Yaounde.

[46] Ayafor, M. (2000) Kamtok: The Ultimate Unifying Common National Language for Cameroon. Carrier Pidgin, 28, 4-6.

[47] Fontem, A.N. (2004) Pidgin Influence on Anglophone English Language Proficiency in Bamenda, NW Cameroon. Unpublished PhD Thesis, University of Ibadan, Nigeria.

[48] Fontem, A.N. and Oyetade, S.O. (2008) Declining Anglophone English Language Proficiency: What Factors Should Be Considered? In: Harrow, K. and Mpoche, K., Eds., Language, Literature and Education in Multicultural Societies. Collaborative Research of Africa, Cambridge Scholarrs Publishing, Cambridge, 121-138.

[49] Neba, A.N., Chibaka, E.F. and Atindogbe, G.G. (2006) Cameroon Pidgin English (CPE) as a Tool for Empowerment and National Development. African Study Monographs, 27, 39-61. 
[50] Kouega, J.P. (1999) Some Major Speech Traits of Cameroon Media News in English. English Studies, 80, 540-555. https://doi.org/10.1080/00138389908599209

[51] Kouega, J.P. (2008) Market Transactions in Cameroon Pidgin English (CPE) Annals of the Faculty of Arts, Letters and Social Sciences. University of Yaounde, 1, 113-136.

[52] Sinclair, J.M. and Coulthard, M. (1975) Towards an Analysis of Discourse: The English Used by Teachers and Pupils. O.U.P., London.

[53] Kouega, J.P. (2009) Telephone Openings and Goodbyes in Cameroon Pidgin English (CPE) Annals of the Faculty of Arts, Letters and Social Sciences. University of Yaounde 1, 45-60.

[54] Schegloff, E.A. and Sacks, H. (1973) Opening up Closings. Semiotica, 8, 289-327. https://doi.org/10.1515/semi.1973.8.4.289

[55] Coronel-Molina, S.M. (1998) Openings and Closings in Telephone Conversations between Native Spanish Speakers. Working Papers in Educational Linguistics, University of Pennsylvania, Vol. 14, 51-67.

[56] Mieder, W. (2004) Proverbs: A Handbook. Greenwood Press, Westport.

[57] Lindstromberg, S. (2012) Consonance in English Proverbs and Collocations. http://www.hltmag.co.uk/aug12/mart03.htm

[58] Taha, A.T. (2011) Proverbs in a Threatened Language Variety in Africa. California Linguistic Notes, 36, 1-19.

[59] Owomoyela, O. (2005) Yoruba Proverbs. University of Nebraska Press, Nebraska.

[60] Bamgbose, A. (1968) The Form of Yoruba Proverbs. ODU, 4, 74-86.

[61] MacCoinnigh, M. (2013) Syntactic Structures in Irish-Language Proverbs. http://www.academia.edu/1858455/Syntactic_Structures_in_Irish-Language_Prover bs

[62] Kouega, J.P. (2007) A Dictionary of Cameroon English Usage. Peter Lang, Berne.

[63] Mieder, W. (1985) Popular Views of the Proverb. Proverbium: Yearbook of International Proverb Scholarship, 2, 109-143.

[64] Todd, L. (1971) West Cameroon Pidgin Proverbs. Journal of West Africa Linguistics, 8, 85-100.

[65] Dundes, A. (1975) On the Structure of the Proverb. Proverbium, 25, 961-973. 